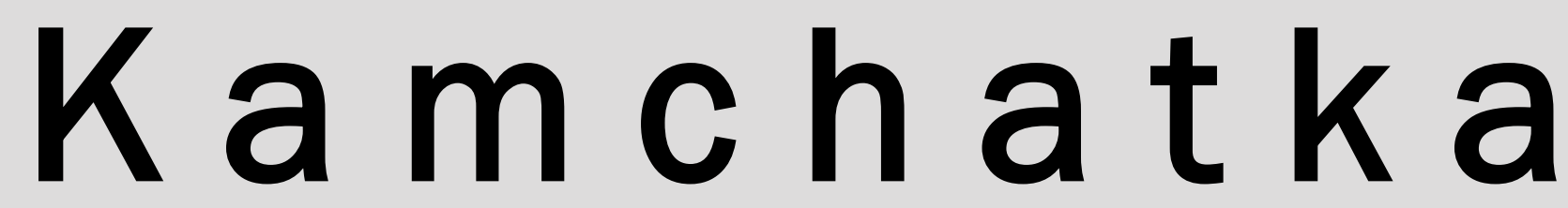

Revista de análisis cultural

N. 12

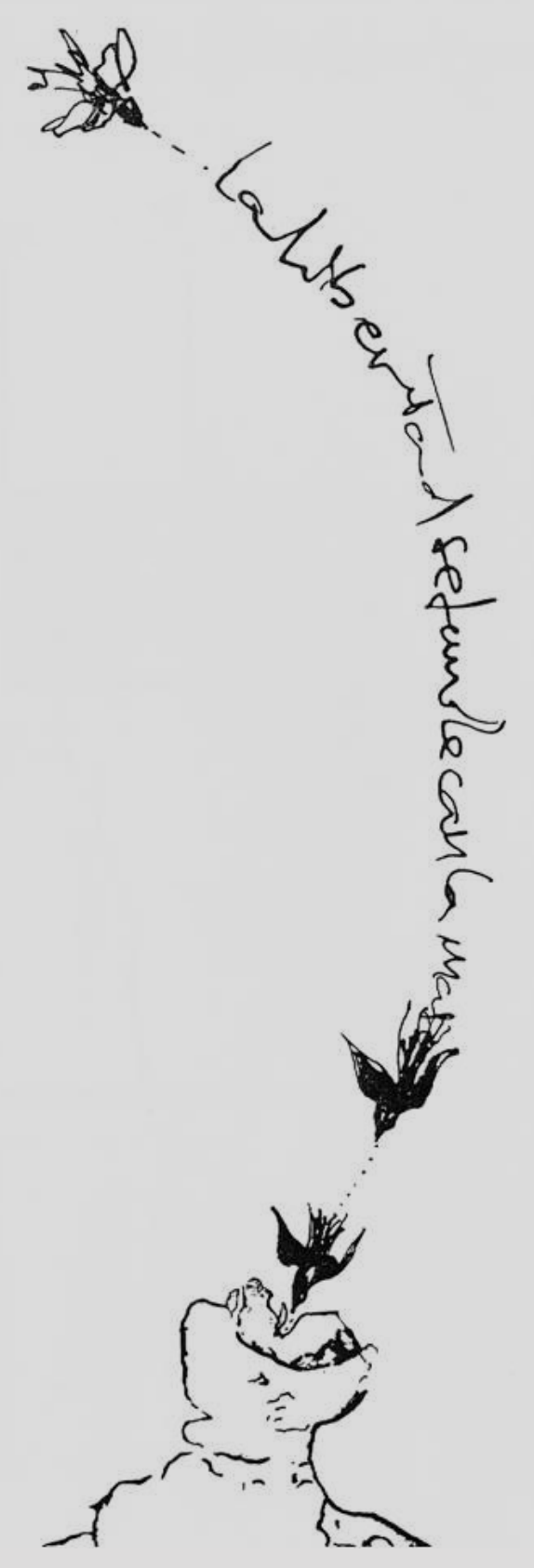

Experimentación poética y contracultura

en contextos dictatoriales ibéricos y latinoamericanos (1960-1990): colectivos, acciones y reacciones

Coordinado por Mercè Picornell y Maria Victòria Parra Moyà 


\title{
EXPERIMENTACIÓN POÉTICA Y CONTRACULTURA EN CONTEXTOS DICTATORIALES IBÉRICOS Y LATINOAMERICANOS (1960-1990): COLECTIVOS, ACCIONES Y REACCIONES
}

\author{
KAMCHATKA. REVISTA DE ANÁLISIS CULTURAL 12 (2018)
}

Monográfico coordinado por Mercè PiCORnell y MARIA Victòria PARRA MoYÀ

Mercè PiCORnell y MARIA Victòria PARRA MoYÀ. Experimentación poética y contracultura en contextos dictatoriales ibéricos y latinoamericanos (1960-1990): colectivos, acciones y reacciones.

JUAN GONZALEZ Granja. Los tzánticos amenazan la ciudad: la performance poética de la indig-nación en el Ecuador moderno.

MALENA LA RocCA. "Rompiendo la piñata del Mundial". Los usos de la fiesta en montajes teatrales, recitales y acciones callejeras durante la última dictadura cívicomilitar argentina.

Pauline Medea Bachmann. Poesía en circulación. Estéticas politizadas entre exposición, documentación y lectura en el Cono Sur.

JĖssica Pujol Duran. Beau Geste Press: a Liminal Communitas across the New Avant-gardes.

Alberto Valverde Otero. El Grupo Rompente (1975-1983). Un viaje $229-251$ inesperado por la Transición en el campo literario gallego.

IratXe RetOlazA. Poéticas experimentales en la resistencia cultural vasca: 'Isturitzetik Tolosan Barru' (1969).

MerCè PiCornell. Campo literario y reconstrucción democrática. Dos poéticas estratégicas y una interpelación en la poesía chilena.

MARIA ViCTÒRIA PARRA MOYÀ. Una cata de 'Sopa de letras' (1976).

$333-369$

$371-404$

$405-432$ 


\title{
DOSSIER
}

\section{EXPERIMENTACIÓN POÉTICA Y CONTRACULTURA EN CONTEXTOS DICTATORIALES IBÉRICOS Y LATINOAMERICANOS (1960-1990): COLECTIVOS, ACCIONES Y REACCIONES}

\author{
MARIA VICTÒRIA PARRA Y MERCÈ PiCORNELL. \\ LiCECT. UNIVERSITAT DE LES ILLES BALEARS (EsPAÑA) \\ mercepicornell@gmail.com parramoyavictoria@gmail.com
}

Este dossier reúne siete artículos y una antología comentada de textos que versan sobre formas creativas de experimentación en contextos dictatoriales iberoamericanos de finales del siglo XX. ${ }^{1}$ El eje histórico se sitúa en el complejo espacio de coincidencia temporal que se da entre distintas fases de los regímenes dictatoriales en los contextos ibérico y latinoamericano y la revitalización de ciertas propuestas de experimentación poética que, en algunos casos, confluyen con la recepción y apropiación de la contracultura. Tomar la dictadura como marco contextual no significa construir, a partir de las fechas de inicio y final de las dictaduras iberoamericanas, un "período" en el que buscar semejanzas. La diversidad de inicios y de finales de los gobiernos autoritarios, así como la diferencia entre sus aparatos represivos y sus transiciones a modelos democráticos hace infructuoso este propósito. Partimos de la idea que esta "coincidencia" dictatorial determina la configuración de lo experimental en los países en los que se produce, una determinación que tiene que ver, entre otros factores, con su dimensión política. Sin embargo, los artículos reunidos en este monográfico muestran, desde su diversidad, cómo la intersección de lo político con lo poético no se vincula directamente al contenido de los discursos que se difunden desde un género concreto o una modalización específica, más o menos testimonial. No se expresa, ni siquiera, necesariamente, mediante un compromiso explícito de resistencia respecto a los discursos de la autoridad. Puede concretarse en poéticas puramente líricas pero que se promuevan desde la colaboración y que, desde su misma acción en común, contradigan la política del miedo que a menudo acompaña las políticas autoritarias. Pueden, simplemente, ensayar formas de disenso dentro del campo literario, un disenso que deviene político en tanto que contradice el discurso único del régimen dictatorial. Pueden, también generar espacios de subjetivación, esto es, según Jacques Rancière (1996), nuevos lugares donde contar la propia identidad y donde hacer visible la diversidad de maneras de ser y de estar.

\footnotetext{
1 Esta propuesta está vinculada al proyecto: "Nous subjectes en la creació catalana contemporània: espais d'enunciació i espais de recepció en les poètiques liminars" (Ministerio de Economía y Competitividad, FFI2015-65110-P).
}

Parra, Maria Victòria y Picornell, Mercè.“Experimentación poética y contracultura en contextos dictatoriales ibéricos y latinoamericanos: (1960-1990): colectivos, acciones y reacciones” Kamchatkea. Revista de análisis cultural 12 (Diciembre 2018): 221-225. DOI: 10.7203/KAM.12.13370 ISSN: 2340-1869

Dossier Experimentación poética y contracultura en contextos dictatoriales 
En este marco, la experimentación poética no se define sólo como una continuación de una tradición vanguardista, ni tampoco como una ruptura necesaria respecto a una expresión lírica más tradicional. Tiene que ver, también, con una innovación respecto a los espacios de difusión donde, entre otras cosas, a menudo se proponen nuevas formas de autoría y colaboración entre creadores. El estudio de las dinámicas grupales desafía las formas convencionales de la crítica literaria, más acostumbrada al estudio de la obra publicada o de la trayectoria de autor. Esta misma dificultad crítica es uno de los valores de transgresión de lo experimental que, cuando recurre a formatos que no son de imprenta o se difunde en circuitos sumergidos, escapa de las lógicas de archivo convencionales. Mucho se ha hablado ya sobre la dificultad de definir la poesía experimental (ver, por ejemplo, Cussen 2010). Utilizamos aquí el término en toda su apertura y desde el conocimiento que su sentido no es el mismo en las diferentes tradiciones literarias que tomamos como campo de estudio. Lo usamos también desde la conciencia que cada tradición crítica ha colocado este espacio de apertura en un lugar concreto del campo literario y lo ha denominado de formas diversas. Así, por ejemplo, Óscar Galindo (2009) habla de "neovanguardias" para los contextos chileno, argentino y peruano; Álvaro Miranda (1988) identifica una línea "experimental-lingüística" en la producción uruguaya de la que denomina "generación de resistencia", donde la poesía visual tendrá fuerte presencia, como la tiene coetáneamente en el contexto portugués. El concepto de "resistencia" que introduce Miranda resulta complejo y puede usarse con un sentido revulsivo o referirse a una producción reactiva (resistencialista) que se vería superada por unas poéticas que se pretenden de oposición o creación al margen del poder. Así ocurre, por ejemplo, en el caso catalán, donde el término "textualista" ha sido asociado a menudo a la producción más transgresora frente a una poesía "realista" o "social", que se considera "de resistencia" (Pons et al 2007). Lo mismo ocurre con la recepción de la contracultura y con su grado de permeabilidad o influencia en los entornos intelectuales y literarios. Si en Brasil, según ha estudiado Christopher Dunn (2016), su incidencia se produce en plena dictadura y buscando espacios de denuncia de la represión, en el contexto peruano, la versión andesgraund del movimiento Kloaka (1982-1984) surge en un contexto postdictatorial, cosa que no atenuará su voluntad de denuncia, pero sí, quizás, sus medios de expresión pública.

Los artículos reunidos en este dossier muestran formas muy diversas de formalización de lo experimental en contextos autoritarios. Desde su diversidad ejemplifican por lo menos tres líneas de actuación, que cabría confirmar si se dan también en contextos no representados en nuestro dossier. La primera tiene que ver con una reinvención de los lugares donde difundir la creación. ${ }^{2}$ No se trata aquí simplemente de una "recuperación" del espacio público, sino con el cambio en los usos de los espacios y de los circuitos de difusión cultural. Lo encontramos, por ejemplo, en la actuación del Movimiento Tzántzico que analiza Juan Carlos González Granja, esto es, del grupo de poetas ecuatorianos que pretendían crear un revulsivo en un panorama cultural tradicionalista y cómplice del poder durante los años de la Junta Militar (1963-1966). Las prácticas performativas de este grupo se presentan como rituales que se escenifican en espacios públicos y se contagian del lenguaje "de la calle". Cuando se plantean en lugares de cultura, desubican al público acostumbrado al recital pausado y cómodo. También Malena La Rocca

\footnotetext{
2 Para una aproximación a otros contextos desde el arte y la performatividad ver el volumen Subversiones artísticas en contextos autoritarios y otras formas de intervencionismo estatal, editado por Laia Manonelles y Víctor Ramírez (2018).
} 
estudia la creación de un mapa de espacios alternativos en Argentina durante la dictadura. Aquí, la resistencia a la autoridad se plantea desde la creación de espacios festivos, donde la creación no está dominada por un simple actor, sino escenificada desde la acción de compartir un espacio de goce. El lenguaje con el que se experimenta en estos nuevos espacios no es tanto la poesía como el teatro -la Escuela de Mimo Contemporáneo, el Taller de Investigaciones Teatrales (Buenos Aires), el Grupo de Arte Experimental Cucaño (Rosario) - o la música -la banda de rock Patricio Rey y sus Redonditos de Ricota (La Plata).

En su diversidad, estas iniciativas tienen también en común una segunda línea de actuación sobre la que versan los artículos aquí reunidos y que tiene que ver con la construcción de vínculos colaborativos que desafían la univocidad de la creación cultural. Lo político en lo experimental antiautoritario tiene que ver con la posibilidad de crear en común. En este sentido, desafía no sólo la individuación y la sospecha sobre el otro de la dictadura -las listas de nombres, la denuncia al vecino, la sospecha ante lo inesperado-, sino también una crítica literaria tradicional, acostumbrada a respetar las dicotomías obra/autor o autor/lector. Desde lo performativo común, el autor no es un individuo y la obra puede ser fruto de un proceso en común, que difumina las tareas del creador y el receptor. En el artículo de Pauline Medea Bachmann, se estudia el desarrollo de las prácticas de poesía experimental en el Cono Sur de Latinoamérica como fruto de una circulación transnacional de obras y creadores. La red estudiada compara la obra del uruguayo Clemente Padín, el chileno Guillermo Deisler, el argentino Edgardo Antonio Vigo, así como el grupo brasileño poema/processo. En este caso, la politización del producto creado tiene tanto que ver con los aspectos temáticos tratados como con las formas de producción y circulación de las obras. Lo mismo ocurre en las dinámicas colaborativas de creación poética analizadas por Jèssica Pujol Duran, unas prácticas, se afirma, "políticas" pero no necesariamente "politizadas". En su artículo estudia la integración de diversos artistas y poetas latinoamericanos en el exilio en el grupo Fluxus. Uno de los frutos de esta integración sería la colección de volúmenes Beau Geste Press, fundada en Devon (Reino Unido) y activa desde 1971 a 1976 y en la que los artistas implicados compartían las tareas de producción de cada volumen. Esta creación de vínculos sobrepasa la tarea del escritor individual y sitúa su creación en una red interartística. Así ocurre también en las diferentes fases del grupo gallego Rompente (1975-1983) que estudia en su colaboración Alberto Valverde. En este artículo se analizan desde una perspectiva sociológica e historiográfica las dos fases del grupo, que se inician justo en la fecha de la muerte de Franco -Grupo de Resistencia Poética (1975-1977) - y continúan durante los años de la Transición -Grupo de Comunicación Poética (1978-1983). En este caso, la colectividad sirve para proyectar una propuesta transgresora en el campo literario, más que para aunar formas creativas. Se expresa, así, mediante el recital colectivo, la antología de textos o la creación de nuevas colecciones editoriales. Resulta interesante valorar cómo la evolución del colectivo va en paralelo a la posibilidad de acceso a diferentes medios de comunicación -el recital, la autoedición, la editorial, la radio...- así como también a los cambios en su referente de oposición: la dictadura franquista y el poder económico que la mantiene, a la creación de un nuevo orden transicional y a una cultura normativa que justifica su estabilidad.

Valverde propone una revisión del tratamiento historiográfico de la producción de Rompente en el campo literario gallego. El mismo ejercicio se plantea en el artículo de Iratxe 
Retolaza respecto a la recepción del primer volumen de poesía visual vasca. Su capítulo, junto al de Picornell, ejemplifican también una tercera vía característica de las formas de posicionamiento poético en los contextos autoritarios, que tendría que ver con la creación de disenso en el campo cultural. La misma posibilidad de creación de alternativas o de manifestación de diferencias ya supone un ejercicio de pluralidad que los regímenes autoritarios suelen sancionar. Retolaza estudia con detalle el volumen Isturitzetic Tolosan Barru (1969), un libro de artista de JosAnton Artze, desde el punto de vista de su formalización, así como de los diferentes agentes que contribuyen a su composición. Resulta especialmente interesante el estudio de su compleja recepción en el contexto literario vasco del momento, que no dispone de elementos para valorar la colectividad y novedad de una propuesta cuyo componente crítico con el tradicionalismo supone también un disenso respecto a la débil hegemonía constituida desde la resistencia. Finalmente, el artículo de Picornell se propone como una panorámica sobre tres propuestas poéticas en el contexto chileno de la dictadura. Analiza como la coexistencia de fórmulas diferentes de manifestación pública de la expresión poética supone una activación de la posibilidad de generar debate y diferencia en el campo cultural, que es política porque escenifica una posibilidad de disenso. Este artículo final pretende situar algunos de los debates en torno a la producción experimental chilena desde una mirada contextualizada, que puede ser útil sobretodo a los que no conocen con detalle sus manifestaciones.

La propuesta se completa con una antología de Sopa de letras (1976, Palma), poemario poéticoexperimental de los artistas N. Cacho-Chacón, Hugo Diz y Horacio Sapere. Una selección comentada por M. Victòria Parra que pone el foco de atención en el carácter transnacional y subversivo del producto: autoría, producción, temática y difusión.

En suma, este dossier permite identificar a la vez la diversidad de lo experimental y de sus vínculos con lo político, y las sinergias que se producen entre contextos muy diferentes, tanto por la incidencia de los gobiernos autoritarios que los condicionan como por la tradición -de referencia o de ruptura- ante la cual plantean su experimentación. Las editoras somos conscientes de que se trata de una simple cata, a la cual faltaría añadir estudios de caso y estudios sobre tradiciones literarias que no quedan representadas - la española, la catalana, la portuguesa entre muchas otras. Las diferentes propuestas experimentales estudiadas muestran el potencial de la creatividad en común incluso en las situaciones más adversas, y la capacidad de lo literario de inventar lugares donde escapar al control de los discursos represivos, una creatividad y una capacidad que son intrínsecamente políticas, en tanto que generan espacios alternativos y comunitarios de expresión y de debate. Presentamos finalmente este dossier con la voluntad de que la enseñanza de lo ya transitado en los contextos ibéricos y latinoamericanos sirva como inspiración para generar plataformas creativas también en el escenario presente, en el que los cómicos y los nuevos poetas del rap son condenados por criticar el poder mientras que las voces de un autoritarismo, viejo bajo su nueva vestimenta, van vociferando su odio. 
BIBLIOGRAFÍA

CusSEN, Felipe. "Poesía experimental: algunas propuestas críticas". Experimental poetics 0 (2010).

Dunn, Christopher (2016). Contracultura. Alterantive Arts and Social Transformation in Authoritarian Brazil. Chapel Hill: University of North Caroline Press.

GALINDO, Oscar. "Neovanguardias en la poesía del cono sur: los 70 y sus alrededores". Estudios filológicos 44 (2009): 67-80.

MANONELLES, Laia, RAmíREZ, Víctor (eds.) (2018). Subversiones artísticas en contextos autoritarios y otras formas de intervencionismo estatal. Palma: Edicions UIB.

MirANDA, Álvaro. "Aproximación a la poesía uruguaya de la Generación de la Resistencia (1973-1985)". Río de la Plata, 7 (1988). reproducido en Letras Uruguay.

PONS, Margalida et al (2007). Textualisme $i$ subversió. Barcelona: Publicacions de l'Abadia de Montserrat.

RanCIÈre, Jacques (1996). El desacuerdo. Política y filosofía. Buenos Aires: Nueva Visión. 